\title{
Evaluation of Air Sampling and Detection Methods to Quantify Airborne Ascospores of Sclerotinia sclerotiorum
}

\author{
M. L. Parker and M. R. McDonald, Department of Plant Agriculture, and G. J. Boland, School of Environmental Sciences, University \\ of Guelph, Guelph, ON, Canada N1G 2W1
}

\begin{abstract}
Parker, M. L., McDonald, M. R., and Boland, G. J. 2014. Evaluation of air sampling and detection methods to quantify airborne ascospores of Sclerotinia sclerotiorum. Plant Dis. 98:32-42.

Detection and quantification of airborne ascospores as a component of the Sclerotinia rot of carrot (SRC) forecast model is currently accomplished using the blue plate test (BPT), which uses Sclerotinia semiselective medium (SSM). A quantitative polymerase chain reaction (qPCR) assay was developed to reduce the time to specifically quantify ascospores of Sclerotinia sclerotiorum from air samples collected using a Burkard Multi-Vial Cyclone Sampler. The qPCR assay was highly sensitive and detected DNA from 0.5 to $5 \times 10^{4}$ ascospores within a linear range $\left(R^{2}=0.99\right)$. The $\mathrm{qPCR}$ assay was used to quantify ascospores of $S$. sclerotiorum in air samples collected over three growing seasons. Initial SRC disease was observed 8 and 34 days following

detection of 9.5 and 2 ascospores $\mathrm{m}^{-3}$ of air, respectively. Results from air samples collected using an Andersen N6 Sampler and the qPCR assay were compared with the BPT. Ascospore counts from a Burkard Sampler coupled with the qPCR assay and the BPT followed similar trends. In general, fewer ascospores were detected and bioaerosol sampling efficiency was low using an Anderson Sampler. Three days were required to confirm the number of ascospores using SSM in the BPT and with an Andersen Sampler, whereas results from a Burkard Sampler coupled with the qPCR assay can provide results within $5 \mathrm{~h}$ of air sampling. The choice of method will depend on the available resources.
\end{abstract}

Sclerotinia sclerotiorum (Lib) de Bary is a notoriously destructive pathogen of a broad range of economically important crops, including oilseeds, vegetables, and pulses (13). Sclerotinia rot of carrot (SRC) is an important disease of carrot where epidemics occur sporadically but infection can be severe, particularly in postharvest storage (33). The disease is bicyclic and infects foliage and, occasionally, roots in the field followed by postharvest spread on roots in storage (33). Primary infection in the field begins on lodged, senesced leaves in the furrow between rows of carrot and advances down the petiole to infect the crown (34). Field-infected crowns are the primary source of inoculum for stored carrot roots. The pathogen overwinters in the soil or on crop debris as sclerotia which, under suitable environmental conditions, germinate carpogenically to produce apothecia from which ascospores are released $(2,41)$. Canopy closure is critical in the development of Sclerotinia diseases because sclerotial germination and ascospore development require prolonged, moist conditions created under a closed canopy, which further maintains leaf wetness for infection $(10,11,17,18$, $34,41)$. Sclerotinia epidemics are principally initiated by airborne ascospores originating from apothecia located within cropping fields and from external sources $(1,10,12,22,27,56)$.

The sporadic occurrence of diseases caused by $S$. sclerotiorum has prompted the development of disease forecast models to optimize the timing of management practices against $S$. sclerotiorum in carrot $(22,34)$, canola $(14,30)$, bean $(29)$, and lettuce $(17,18)$. Sclerotinia forecast models assess environmental and cropping variables to estimate the risk of disease or to predict the presence of inoculum $(17,18,29,30,51,53)$. Alternatively, forecast models employ methods to directly detect and quantify ascospores of $S$. sclerotiorum using air sampling methods $(5,22,25,27,39,49,50)$ or by culturing infected but symptomless plant tissue on Sclerotiniaselective media (SSM) $(14,25,37,51,52)$. The concentration of

Corresponding author: M. L. Parker, E-mail: m.parker@cgiar.org

Accepted for publication 15 July 2013.

http://dx.doi.org/10.1094/PDIS-02-13-0163-RE

(c) 2014 The American Phytopathological Society airborne ascospores of $S$. sclerotiorum, estimated using microscopy, culturing, or DNA-based methods for identification, was related to subsequent disease development in carrot, canola, potato, and sunflower $(6,22,27,40,49)$.

The current SRC forecast model estimates disease risk by detecting airborne ascospores and assessing canopy development (22,34). An alternative SRC forecast model measures soil matric potential and canopy growth and applies these data in a 7-day risk algorithm. The blue plate test (BPT) has been validated as a reliable indicator of the quantity of airborne ascospores $(22,34)$. A fungicide application program guided by ascospore counts resulted in the lowest number of fungicide applications over 2 years (total of three applications), with equivalent efficacy against SRC as an alternative model applying soil matric potential and canopy growth data in a risk algorithm (total of 8 sprays) and a biweekly calendar application schedule (total 10 sprays) (22).

Airborne ascospores have been identified using detection methods based on SSM $(5,22,27,50)$. Identification is confirmed by the development of yellow halos around colonies resulting from a change in $\mathrm{pH}$ indicator contained in the medium in the presence of oxalic acid secreted by $S$. sclerotiorum. In the BPT, ascospores contained in bioaerosol are passively deposited onto exposed petri plates containing SSM. Andersen air samplers actively collect bioaerosol using a vacuum to draw air through a perforated disc in a chamber, depositing bioaerosol onto culture medium contained within a plate placed immediately underneath the disk (3). Other air-sampling methods, such as a rotorod or Burkard volumetric samplers, use microscopy to identify ascospores that have impacted a waxy-coated surface on a transparent film $(20,23)$.

Quantitative polymerase chain reaction (qPCR)-based methods have been developed to specifically detect and quantify microorganisms from air, plant, or soil samples $(7,9,16,38,42,49,55,59)$. The advantages of $\mathrm{qPCR}$ are its high sensitivity and specificity. Low concentrations of a target microorganism can be detected among a background of DNA from diverse organisms during the early stages of disease development, prior to the appearance of symptoms (35). Some models of air samplers, such as the Burkard Cyclone Sampler, are compatible for use with PCR-based detection methods because DNA can be extracted directly from collection 
tubes, eliminating any transfer steps from tape or rods as used in other air samplers (57).

The BPT is the current ascospore detection method in the SRC forecast model. Limitations of the BPT include a 3-day delay from air sampling to a diagnosis and inaccurate readings after a rain event $(22,50)$. Burkard and Andersen Samplers are volumetric, using a vacuum to actively collect bioaerosol at a known flow rate. Burkard Samplers are equipped with a wind vane to position the intake valve to face the prevailing winds. Andersen Samplers are positioned horizontally to the airflow; therefore, the collection volume is independent of the direction of the wind. The BPT relies on positioning petri plates containing SSM on an angle to face the prevailing winds and passive deposition of ascospores carried by the wind. The volume of air impacting the plate varies with the wind speed and direction, which is not always consistent during the sampling period; therefore, ascospore counts and a threshold cannot be standardized. A qPCR assay could rapidly detect airborne ascospores of $S$. sclerotiorum, reducing the time to confirm the presence of inoculum of $S$. sclerotiorum. The objectives of this study were to develop a reliable qPCR assay to detect and quantify ascospores of $S$. sclerotiorum from air samples, and evaluate air sampling methods to determine the most effective method to incorporate into the SRC forecast model.

\section{Materials and Methods}

Primer design. In preliminary experiments, numerous primer sets were screened that targeted the internal transcribed spacer (ITS) region of the ribosomal DNA (rDNA) cluster and the group-I intron of the mitochondrial small-subunit (mt SSU) rRNA (15) for detecting ascospores of $S$. sclerotiorum, including previously reported primer sets $(49,59)$. These primer sets did not pass preliminary specificity or sensitivity tests. Within the ITS region, there were no regions with sufficient variation that a primer could be designed that distinguished $S$. sclerotiorum from Botrytis cinerea Pers. and resulted in an amplicon $<200 \mathrm{bp}$ to ensure adequate primer efficiency. The reported primer targeting the mt SSY rRNA was modified by the authors after inconsistent performance in their laboratory. The limit of detection of the microsatellite primer M13 (59) was $10^{2}$ ascospores.

To design the final primer set for qPCR targeting the mt SSU rRNA, the amplified product generated by the primer set Mit_Ss-F (5'-GCTTTGTGGTGTAGGATCT-3') and Mit_Ss-R (5'-CACGGC AATCAGCATCTAT- $3^{\prime}$ ) that spans the complete sequence of the GenBank accession U07553 was sequenced for S. sclerotiorum, Monilinia vaccinii-corymbosi (J.M. Reade) Honey, Sclerotium cepivorum Berk., and Sclerotinia minor Jagger (sequencing proto$\mathrm{col}$ is described below). The forward and reverse sequences were assembled and aligned using Geneious Pro software (v.5.4.3) to identify variable regions to design a primer set specific for $S$. sclerotiorum. The final primer sequences used for qPCR, Mit(i)_Ss-F (5'-CGAAAGGCTATACGTGGCTGAAGT-3') and Mit(i)_Ss-R (5'-TCCGCGATAATCCATTTCTCTTTC-3'), were designed so that the amplicon was $<200$ bp using AmplifX software (v.1.5.4; http://amplifx.softpedia.com/). The primer set was predicted to generate an amplicon of $122 \mathrm{bp}$. Primers were checked for significant sequence similarity with other DNA sequences using BLAST analysis (blastn at http://www.ncbi.nlm.nih.gov/Blast.cgi). Sequences of the amplicon generated by the Mit(i)_Ss F/R primer set on mycelia (isolate $\mathrm{C} 14$ ) and ascospores of $S$. sclerotiorum (isolate DL) were used as positive controls to compare melt temperatures and DNA sequences of amplified products generated from air samples.

qPCR assay. qPCR reactions were performed in a StepOnePlus Real-Time PCR System (Applied Biosystems) using SYRB Green

Table 1. Isolates of Sclerotinia sclerotiorum, fungi expected to be among the bioaerosol of the Bradford Marsh, and other Ascomycota species used for evaluation of primer specificity in a SYBR quantitative polymerase chain reaction (qPCR) assay with the primer set Mit(i)_Ss F/R and 10 pg of fungal DNA

\begin{tabular}{|c|c|c|c|c|}
\hline Fungal isolates & Origin & Host & Collector & Ct value $^{a}$ \\
\hline \multicolumn{5}{|l|}{ S. sclerotiorum } \\
\hline B1-B4 & Ontario: Bradford Marsh & Bean & M. Parker & $21.5-22.1$ \\
\hline $\mathrm{C} 1-\mathrm{C} 14$ & Ontario: Bradford Marsh & Carrot & M. Parker & $21.2-33.2^{\mathrm{b}}$ \\
\hline C63 & United Kingdom & Carrot & D. Fernando & N/A \\
\hline $\mathrm{DL}$ & Nebraska & Bean & M. G. Boosalis & 22.9 \\
\hline L1-L5, L7-L11 & Ontario: Bradford Marsh & Lettuce & M. Parker & $20.9-32.8^{c}$ \\
\hline L6 & United Kingdom & Lettuce & D. Fernando & N/A \\
\hline L17 & United Kingdom & Lettuce & D. Fernando & 23.7 \\
\hline UF1 & Florida & Unknown & J. Rollins & 23.2 \\
\hline ZQ 33-3-3 & Manitoba & Unknown & D. Fernando & 21.3 \\
\hline ZQ 33-4 & Manitoba & Unknown & D. Fernando & 23.8 \\
\hline ZQ 33-5-4 & Manitoba & Unknown & D. Fernando & 20.6 \\
\hline ZQ 33-5-5 & Manitoba & Unknown & D. Fernando & 21.15 \\
\hline 33 & Manitoba & Unknown & D. Fernando & 26.5 \\
\hline 310 & Ontario: Bradford Marsh & Lettuce & G. Boland & 31.9 \\
\hline 311 & Ontario: Bradford Marsh & Carrot & G. Boland & 33.7 \\
\hline \multicolumn{5}{|l|}{ Bioaerosol organisms ${ }^{\mathrm{d}}$} \\
\hline Alternaria alternata & Ontario & Onion & M. Parker & N/A \\
\hline A. dauci & British Columbia & Carrot & Z. Punja & N/A \\
\hline Botrytis alli & Ontario & Onion & M. Tesfaendrias & N/A \\
\hline B. cinerea & British Columbia & Carrot & Z. Punja & N/A \\
\hline B. cinerea & Ontario & Marigold & M. Parker & N/A \\
\hline B. squamosa & Ontario & Onion & M. Tremblay & N/A \\
\hline Stemphylium vesicarium & Ontario & Onion & M. Parker & N/A \\
\hline \multicolumn{5}{|l|}{ Other Ascomycota species } \\
\hline Monilinia fructicola & Nova Scotia & Peach & P. Hildebrand & N/A \\
\hline M. vaccinii-corymbosi & Nova Scotia & Blueberry & P. Hildebrand & $33.3-34.8$ \\
\hline S. homeocarpa & Ontario & Turfgrass & G. Boland & N/A \\
\hline S. minor & Ontario & Lettuce & G. Boland & $30.6-31.1$ \\
\hline Sclerotium cepivorum & Ontario & Onion & G. Boland & N/A \\
\hline \multicolumn{5}{|c|}{ Unidentified fungi from air samples } \\
\hline Unknowns $1-10$ & Ontario & Air sample & M. Parker & N/A \\
\hline
\end{tabular}

\footnotetext{
a Mean cycle threshold $(\mathrm{Ct})$ of two technical replications from a single qPCR reaction. N/A = no amplification.

${ }^{\mathrm{b}}$ In all, 10 of 15 isolates were detected at $\mathrm{Ct}$ values of 21.2 to 22.0 and 3 isolates had values of 31.9 to 33.7 .

c In all, 8 of 10 isolates were detected at $\mathrm{Ct}$ values of 20.7 to 22.0 and 1 isolate was not detected.

d Organisms expected to be among the bioaerosol of the Bradford Marsh.
} 
I fluorescent dye detection at the University of Guelph Genomics Facility. All reactions were performed in 0.1-ml MicroAmp Fast 96-Well Reaction Plates (Applied Biosystems) in a reaction volume of $20 \mu \mathrm{l}$ containing $5 \mu \mathrm{l}$ of DNA extract, $10 \mu \mathrm{l}$ of PerfeCTa SYBR FastMix (ROX; Quanta Biosciences, Inc.), $2 \mu \mathrm{l}$ of each highly purified salt-free primer $(300 \mathrm{nM})$, and $3 \mu \mathrm{l}$ of PCR-grade sterile water. The amplification and quantification conditions were an initial denaturation at $95^{\circ} \mathrm{C}$ for $2 \mathrm{~min}$, followed by 40 cycles at

Table 2. Assays of air samples for Sclerotinia sclerotiorum using a SYBR quantitative polymerase chain reaction (qPCR) assay at the University of Guelph-Muck Crops Research Station (MCRS), Bradford Marsh, ON, Canada in 2008, 2009, and 2011

\begin{tabular}{|c|c|c|}
\hline Air sample date & $\begin{array}{c}\text { S. sclerotiorum ascospore } \\
(\text { mean } \mathrm{Ct})^{\mathrm{a}}\end{array}$ & $\mathbf{S D}^{\mathbf{b}}$ \\
\hline \multicolumn{3}{|l|}{2008} \\
\hline 26 August & 30.8 & 0.2 \\
\hline 29 August & $34.6^{\mathrm{c}}$ & 2.2 \\
\hline 2 September & 30.8 & 1.2 \\
\hline 5 September & $N / A^{c}$ & $\ldots$ \\
\hline 10 September & 32.2 & 0.8 \\
\hline 12 September & 31.9 & 1.5 \\
\hline 16 September & 28.6 & 0.1 \\
\hline 19 September & 28.8 & 0.3 \\
\hline 23 September & 28.6 & 0.1 \\
\hline 24 September & 25.6 & 0.1 \\
\hline 1 October & 32.2 & 1.0 \\
\hline 3 October & $35.2^{\mathrm{c}}$ & 1.3 \\
\hline 8 October & 31.2 & 1.1 \\
\hline \multicolumn{3}{|l|}{2009} \\
\hline 30 July & 28.3 & 0.2 \\
\hline 5 August & 28.2 & 0.3 \\
\hline 7 August & 33.1 & 0.3 \\
\hline 13 August & 34.9 & 0.3 \\
\hline 17 August & 28.6 & 0.3 \\
\hline 20 August & 27.5 & 0.2 \\
\hline 25 August & 28.5 & 0.2 \\
\hline 27 August & 28.2 & 0.2 \\
\hline 1 September & 28.5 & 0.1 \\
\hline 4 September & $32.7^{\mathrm{d}}$ & 0.8 \\
\hline 8 September & 36.2 & 1.9 \\
\hline 11 September & 34.7 & 1.6 \\
\hline 15 September & $30.0^{c}$ & 1.5 \\
\hline 18 September & $\mathrm{N} / \mathrm{A}^{\mathrm{c}}$ & \\
\hline 22 September & 28.0 & 0.2 \\
\hline 25 September & $36.6^{\mathrm{c}}$ & 0.1 \\
\hline 8 October & $30.6^{\mathrm{d}}$ & 0.2 \\
\hline \multicolumn{3}{|l|}{2011} \\
\hline 20 July & 30.5 & 0.2 \\
\hline 27 July & 32.8 & 0.6 \\
\hline 2 August & $37.3^{\mathrm{e}}$ & 2.7 \\
\hline 9 August & $33.7^{\mathrm{e}}$ & 1.2 \\
\hline 11 August & $33.9^{\mathrm{e}}$ & 1.2 \\
\hline 15 August & N/A & $\ldots$ \\
\hline 18 August & N/A & $\ldots$ \\
\hline 23 August & $33.0^{\mathrm{e}}$ & 0.8 \\
\hline 26 August & $34.4^{\mathrm{e}}$ & 1.7 \\
\hline 30 August & 30.6 & 0.6 \\
\hline 2 September & $36.3^{\mathrm{e}}$ & 1.2 \\
\hline 6 September & $35.2^{\mathrm{e}}$ & 2.3 \\
\hline 9 September & 34.8 & 1.0 \\
\hline 13 September & 31.2 & 0.2 \\
\hline 16 September & $35.9^{\mathrm{e}}$ & 2.4 \\
\hline 20 September & 34.6 & 0.8 \\
\hline
\end{tabular}

${ }^{\text {a }}$ Mean cycle threshold $(\mathrm{Ct})$ of three technical replications. N/A = no amplification.

b $\mathrm{SD}=$ standard deviation.

${ }^{\mathrm{c}}$ Internal control was not detected. The air sample from 15 September 2009 was accepted because the pathogen was detected at concentrations indicating potential disease risk.

${ }^{\mathrm{d}}$ Internal control differed by $>2 \mathrm{Ct}$ values relative to the positive control. The air sample from 8 October 2009 was accepted because the pathogen was detected at concentrations indicating potential disease risk.

${ }^{\mathrm{e}}$ Only two Ct values were included in this air sample; there was no amplification in the third replication. $95^{\circ} \mathrm{C}$ for $1 \mathrm{~s}$ and annealing for $30 \mathrm{~s}$ at $60^{\circ} \mathrm{C}$. After the final amplification cycle, a melting curve profile was obtained by heating to $95^{\circ} \mathrm{C}$, cooling to $65^{\circ} \mathrm{C}$, and incrementally heating to $95^{\circ} \mathrm{C}$ at a rate of $0.3^{\circ} \mathrm{C} / \mathrm{s}$ to detect whether unspecific products or primer-dimers occurred, as indicated by more than a single peak in the profile. The threshold line or level of detection was set at a fluorescence ( $\Delta \mathrm{Rn}$, measure of the reporter signal) of 0.2 . A cycle threshold $(\mathrm{Ct})$ was scored positive between 17 and 34 and negative above 34, because this was the limit of detection of the lowest concentration of ascospores tested (54). All reactions were performed using two technical replicates, except that reactions of DNA extracted from air samples were performed in four technical replicates for each sampling date. DNA extracted from S. sclerotiorum and a no-template reaction were used as positive and negative controls, respectively.

Primer specificity. The specificity of the Mit_Ss F/R primer set in the qPCR assay was tested against DNA isolated from pure cultures of mycelia from 40 isolates of S. sclerotiorum and 21 other fungal species expected to be in bioaerosol, which included fungi from 10 colonies with differing morphology that were isolated from experimental air samples (Table 1). Four of these fungal colonies were identified as belonging to the genera Cladosporium, Epicoccum, Penicillium, and Ulocladium, common organisms among bioaerosol (4). Isolates B1-B4, C1-14, L1-5, and L7-11 of S. sclerotiorum obtained from the Bradford Marsh, ON, Canada were isolated by plating disinfested sclerotia obtained from infected host tissue onto potato dextrose agar (PDA; Difco Laboratories) to germinate. Mycelia from germinated sclerotia were transferred to PDA lined with cellophane (Flexel Sales Inc.), followed by DNA extraction using the Power Soil DNA Isolation Kit (MoBio Laboratories Inc.). Samples were stored at $-20^{\circ} \mathrm{C}$. Each qPCR reaction contained $10 \mathrm{pg}$ of fungal DNA, quantified using a NanoDrop 1000 spectrophotometer (Thermo Scientific). All reactions were performed twice on two different days using two technical replicates of each isolate.

Ascospore dilution series to establish a qPCR standard curve. Ascospores produced from apothecia under sterile conditions (courtesy of J. Cowan, University of Guelph, Guelph, ON, Canada) were suspended in extraction buffer, consisting of $2 \%$ hexadecyltrimethylammonium bromide (CTAB), $100 \mathrm{mM}$ TrisHCL (pH 8.0), $1.4 \mathrm{mM} \mathrm{NaCl}$, and $20 \mathrm{mM}$ EDTA. Ascospores were counted using a hemocytometer and the concentration of the ascospore suspension was adjusted to $5 \times 10^{4}$ spores in $100 \mu \mathrm{l}$ of CTAB. Ascospore suspensions were mechanically disrupted in three freeze-thaw cycles and DNA was extracted as described above. Samples were kept frozen at $-20^{\circ} \mathrm{C}$.

An ascospore standard curve was established by suspending $5 \times$ $10^{4}$ ascospores in $100 \mu \mathrm{l}$ of CTAB. The ascospores were mechanically disrupted by three freeze-thaw cycles consisting of $2 \mathrm{~min}$ in liquid nitrogen followed by $2 \mathrm{~min}$ at $70^{\circ} \mathrm{C}$, with the final thaw extended to $30 \mathrm{~min}$, followed by DNA extraction using the Power Soil DNA Isolation Kit. The DNA extract was serially diluted 10fold six times to 0.5 ascospores, which included a 2 -fold dilution from the $5 \times 10^{0}$ ascospore suspension. DNA extracted from four independent ascospore suspensions was used to generate the ascospore standard curve and determine the minimum number of ascospores that could be detected using qPCR. To ensure that the internal control did not interfere with the qPCR reaction, each concentration in three independent dilution series was spiked with $2 \times 10^{6}$ copies of the internal control plasmid (described below). Regression analysis was used to establish the relationship between the $\mathrm{Ct}$ value and the logarithm of the number of ascospores. The PROC REG procedure of SAS (v. 9.2; SAS Institute) was used to estimate the slope and intercept regression parameters. Primer efficiency was calculated according to the equation $\mathrm{E}=\left[10^{(-1 / \text { slope })}\right]$ $-1(54)$

Internal control. An internal control consisting of a 550-bp fragment from the Nicotiana tabacum fucosyltransferase (NTFT) gene inserted into the cloning vector pCR 2.1-TOPO (courtesy of Dr. J. C. Hall, University of Guelph, ON, Canada) was included as 
Table 3. Detection of ascospores of Sclerotinia sclerotiorum using the blue plate test (BPT), an Andersen N-6 Single-Stage Sampler (N-6), and a Burkard Multi-Vial Cyclone Sampler coupled with a quantitative polymerase chain reaction (qPCR) at three air sampling sites in the Bradford Marsh, Ontario over 3 years $^{\mathrm{a}}$

\begin{tabular}{|c|c|c|c|c|c|c|c|}
\hline & \multicolumn{3}{|c|}{ Experimental 1} & \multicolumn{2}{|c|}{ Commercial 1} & \multicolumn{2}{|c|}{ Commercial 2} \\
\hline & $\mathbf{B P T}^{\mathbf{a}}$ & $N-6^{b}$ & Burkard $^{\mathrm{c}}$ & BPT & N-6 & BPT & N-6 \\
\hline \multicolumn{8}{|l|}{2008} \\
\hline 29 July & 3 & 0 & $\ldots{ }^{\mathrm{d}}$ & 2 & $\ldots$ & 0 & $\ldots$ \\
\hline 5 August & 12 & 2 & $\begin{array}{l}\cdots \\
\cdots\end{array}$ & 2 & $\ddot{0}$ & 1 & $\ddot{0}$ \\
\hline 8 August & 3 & 2 & $\cdots$ & 29 & $\ldots$ & 2 & $\ldots$ \\
\hline 12 August & 2 & 2 & $\ldots$ & 4 & 0 & 2 & 1 \\
\hline 15 August & 3 & 0 & $\begin{array}{l}\cdots \\
\cdots\end{array}$ & 1 & $\ldots$ & 3 & $\ldots$ \\
\hline 19 August & $<1$ & 2 & $\begin{array}{l}\cdots \\
\cdots\end{array}$ & 1 & $\dddot{m}$ & $<1$ & 1 \\
\hline 2 August2 & 3 & 0 & $\ldots$ & 1 & 0 & $<1$ & 0 \\
\hline 26 August & 0 & 0 & 5 & $<1$ & 0 & 0 & 0 \\
\hline 29 August & $<1$ & 0 & $<1$ & $<1$ & 0 & 0 & 0 \\
\hline 2 September & $<1$ & 0 & 5 & $<1$ & 0 & $<1$ & 0 \\
\hline 5 September & $<1$ & 0 & 0 & 0 & 0 & 0 & 0 \\
\hline 10 September & $<1$ & 1 & 2 & $<1$ & 0 & 0 & 2 \\
\hline 12 September & 4 & $\ldots$ & 2 & $<1$ & $\ldots$ & $\ldots$ & $\ldots$ \\
\hline 16 September & $<1$ & $\begin{array}{l}\cdots \\
\ldots\end{array}$ & 23 & 0 & $\begin{array}{l}\cdots \\
\cdots\end{array}$ & 0 & $\cdots$ \\
\hline 19 September & $<1$ & 1 & 20 & $<1$ & 2 & 0 & 0 \\
\hline 23 September & $<1$ & $\ldots$ & 22 & $<1$ & $\ldots$ & $<1$ & . \\
\hline 24 September & 2 & 1 & 178 & 2 & $\dddot{2}$ & 2 & $\dot{0}$ \\
\hline 1 October & $<1$ & $\ldots$ & 2 & 0 & $\ldots$ & 0 & $\ldots$ \\
\hline 3 October & $<1$ & 1 & $<1$ & $<1$ & 4 & 1 & 0 \\
\hline 8 October & $<1$ & $\ldots$ & 4 & $<1$ & $\ldots$ & 1 & $\ldots$ \\
\hline \multicolumn{8}{|l|}{2009} \\
\hline 8 July & 0 & $\ldots$ & $\ldots$ & $\ldots$ & $\ldots$ & $\ldots$ & $\ldots$ \\
\hline 15 July & 0 & $\ldots$ & $\ldots$ & $<1$ & $\ldots$ & $\ldots$ & $\ldots$ \\
\hline 24 July & 2 & $\ldots$ & $\ldots$ & 0 & $\ldots$ & $\ldots$ & $\ldots$ \\
\hline 30 July & 7 & $\ldots$ & 29 & 9 & $\ldots$ & 4 & $\ldots$ \\
\hline 5 August & 8 & $\begin{array}{l}\cdots \\
\cdots\end{array}$ & 30 & $<1$ & $\begin{array}{l}\cdots \\
\cdots\end{array}$ & 0 & $\begin{array}{l}\cdots \\
\cdots\end{array}$ \\
\hline 7 August & 22 & 13 & 1 & $<1$ & $\dddot{1}$ & $<1$ & 0 \\
\hline 13 August & 5 & $\ldots$ & $<1$ & $<1$ & $\ldots$ & $\ldots$ & $\ldots$ \\
\hline 17 August & 14 & 6 & 23 & 2 & 0 & 2 & 0 \\
\hline 20 August & 7 & 3 & 48 & 2 & 2 & 2 & 6 \\
\hline 25 August & 0 & 6 & 25 & $<1$ & 1 & 1 & 0 \\
\hline 27 August & 6 & 2 & 30 & 3 & 3 & 3 & $\ldots$ \\
\hline 1 September & $<1$ & 3 & 24 & $<1$ & 0 & $<1$ & 0 \\
\hline 4 September & 1 & 0 & 2 & $<1$ & 0 & 3 & 0 \\
\hline 8 September & $<1$ & 1 & $<1$ & 0 & 0 & 1 & 0 \\
\hline 11 September & 0 & 0 & $<1$ & 0 & 0 & $<1$ & 0 \\
\hline 15 September & 0 & 0 & 9 & 0 & 0 & 0 & 0 \\
\hline 18 September & 0 & 0 & 0 & 0 & 0 & 0 & 0 \\
\hline 22 September & 0 & 0 & 35 & 0 & 0 & 0 & 0 \\
\hline 25 September & 0 & 0 & $<1$ & 0 & 0 & 0 & 0 \\
\hline 29 September & 0 & 0 & $\ldots$ & 0 & 0 & $<1$ & 0 \\
\hline 8 October & 0 & 0 & 6 & 0 & 0 & 0 & 0 \\
\hline 15 October & 0 & 0 & $\ldots$ & 0 & 0 & 0 & 0 \\
\hline \multicolumn{8}{|l|}{2011} \\
\hline 6 July & 0 & $\ldots$ & $\ldots$ & .. & $\ldots$ & $\ldots$ & $\ldots$ \\
\hline 13 July & 0 & $\ldots$ & $\ldots$ & 0 & $\ldots$ & $\ldots$ & $\ldots$ \\
\hline 20 July & 0 & $\ldots$ & 6 & 0 & $\ldots$ & 0 & $\ldots$ \\
\hline 27 July & 0 & $\begin{array}{l}\cdots \\
\cdots\end{array}$ & 1 & 0 & $\begin{array}{l}\cdots \\
\cdots\end{array}$ & 0 & $\cdots$ \\
\hline 2 August & 0 & 0 & $<1$ & 0 & $\ddot{0}$ & 0 & $\ddot{0}$ \\
\hline 9 August & 0 & 0 & $<1$ & $<1$ & 0 & 0 & 0 \\
\hline 11 August & 0 & 0 & $<1$ & 0 & 0 & 0 & 0 \\
\hline 15 August & $<1$ & 0 & 0 & $<1$ & 1 & $<1$ & 0 \\
\hline 18 August & 0 & 0 & 0 & 0 & 0 & 0 & 0 \\
\hline 23 August & 0 & 0 & 1 & 0 & 0 & 0 & 0 \\
\hline 26 August & 0 & $\ldots$ & $<1$ & $<1$ & $\ldots$ & 0 & $\ldots$ \\
\hline 30 August & 0 & $\begin{array}{l}\cdots \\
\ldots\end{array}$ & 6 & 0 & $\begin{array}{l}\cdots \\
\ldots\end{array}$ & 0 & $\cdots$ \\
\hline 2 September & 0 & 0 & $<1$ & 0 & 0 & 0 & 0 \\
\hline 6 September & 0 & 3 & $<1$ & 0 & 0 & 0 & 0 \\
\hline 9 September & 3 & 1 & $<1$ & 8 & 0 & 4 & 0 \\
\hline 13 September & 0 & 0 & 4 & 0 & 0 & 0 & 0 \\
\hline 16 September & 0 & 0 & $<1$ & 0 & 0 & 0 & 0 \\
\hline 20 September & 0 & 0 & $<1$ & 0 & 0 & $<1$ & 0 \\
\hline 28 September & 0 & 0 & $\ldots$ & $\ldots$ & 0 & 1 & 0 \\
\hline
\end{tabular}

a Data are a mean of six plates, each exposed for $3 \mathrm{~h}$ during 0930 to $1330 \mathrm{~h}$.

${ }^{\mathrm{b}}$ Data are total ascospore counts from three plates containing Sclerotinia semiselective media, each exposed for 10 min at an air movement rate of 30 liters $\min ^{-1}$.

${ }^{\mathrm{c}}$ Data are total number of ascospores in an Eppendorf tube collected using a Burkard Sampler that operated from 1000 to $1300 \mathrm{~h}$ at an air movement rate of 16.5 liters $\mathrm{min}^{-1}$ that were detected and quantified using a qPCR assay.

${ }^{\mathrm{d}}$ Symbol: ... indicates data not available. 
an internal reference with each air sample analyzed by qPCR to detect possible inhibitors during DNA extraction and amplification. Primers for the internal control, NTFT-F (5'-CGCTTCAGT GCTTCCACTTT- $3^{\prime}$ ) and NTFT-R (5'-TAGCAGCCGCTTTCA TTTCT- $3^{\prime}$ ) were tested for plasmid specificity against the 22 fungal species listed in Table 1 using $10 \mathrm{pg}$ of DNA purified using the Power Soil DNA Isolation Kit. The internal control was amplified and detected in a separate $\mathrm{qPCR}$ reaction than the air samples and a melt curve profile was generated, as previously described, except that the amplification conditions were 35 cycles at $95^{\circ} \mathrm{C}$ for $1 \mathrm{~s}$ and annealing for $30 \mathrm{~s}$ at $59^{\circ} \mathrm{C}$. All reactions detecting inhibition included two technical replicates of a positive control of $2 \times 10^{6}$ copies of the plasmid extracted alone. A variation in detection of the internal control in an air sample of more than $2 \mathrm{Ct}$ values from
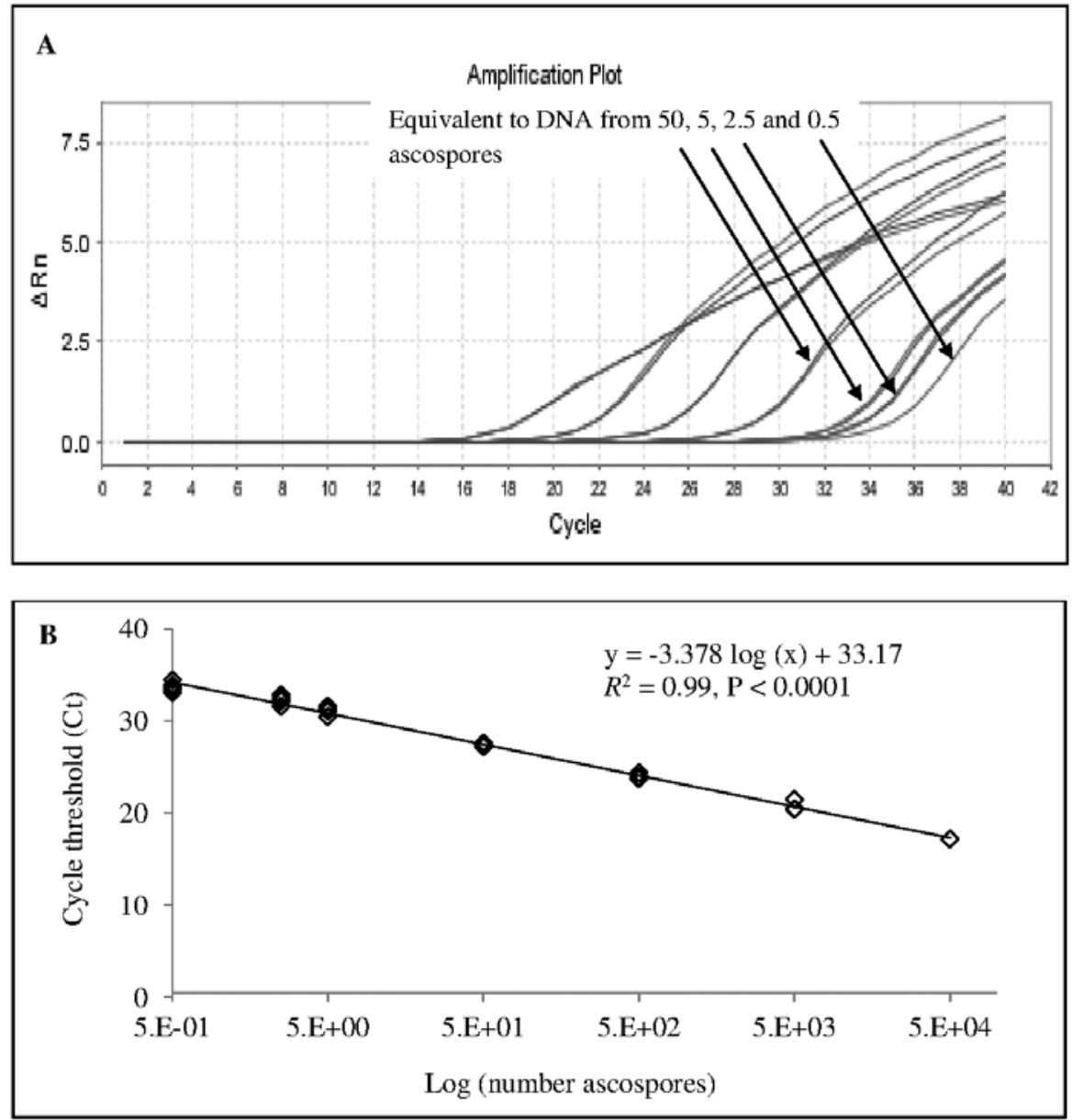

Fig. 1. Quantitative polymerase chain reaction (qPCR) with SYBR Green and the primer set Mit(i)_Ss F/R for detection and quantification of Sclerotinia sclerotiorum ascospores. A, Fluorescence signal relative to the amount of template with fluorescence $(\Delta \mathrm{Rn})$ plotted against cycle threshold (Ct) derived from a 10-fold ascospore dilution series of DNA extracted from $5 \times 10^{4}$ ascospores diluted to 0.5 ascospores. The lowest DNA concentration detected was at 0.5 ascospores at a Ct of $33.74 \pm 0.21$ using primers at a concentration of $300 \mathrm{nM}$. B, Standard curve derived from pooled data of four biological replicate dilution series, each concentration tested in technical triplications, with the $\mathrm{Ct}$ value plotted against the log of the number of ascospores. All dilution series had amplification plots similar to $\mathrm{A}$. Ct values were assessed at $\Delta \mathrm{Rn}$ of 0.2 .

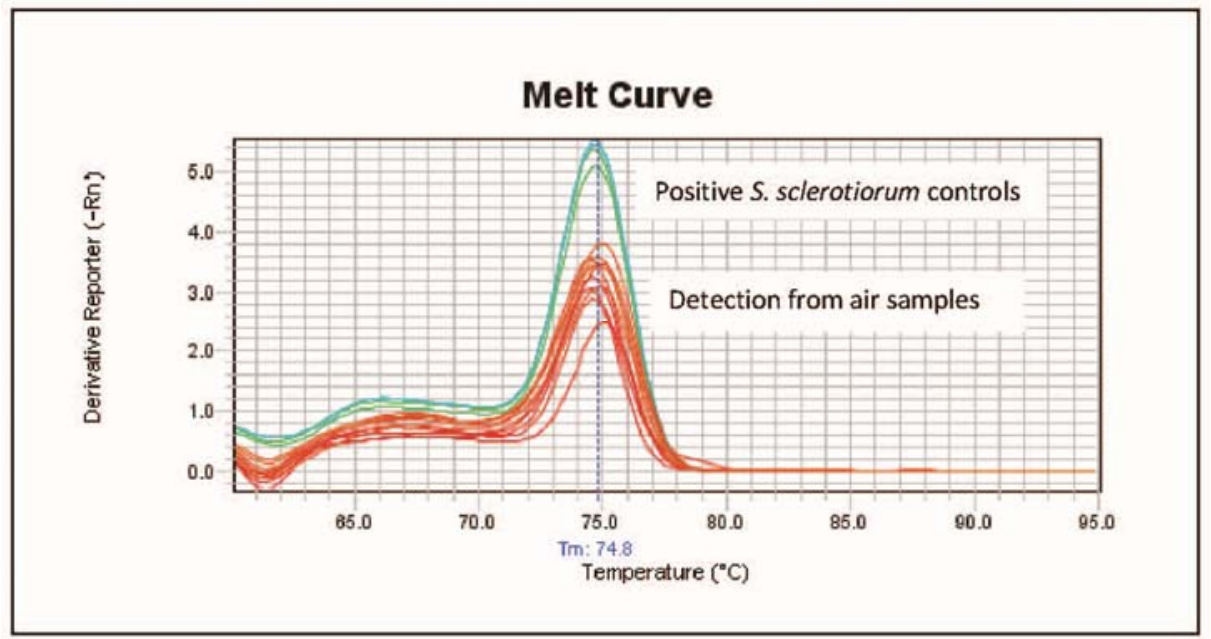

Fig. 2. Melt curve analysis with the derivative of fluorescence reporter plotted as a function of temperature generated during a SYBR quantitative polymerase chain reaction using Mit(i)_Ss F/R primer set for the specific detection of Sclerotinia sclerotiorum ascospores from air samples (amplified product $74.8^{\circ} \mathrm{C}$ ). 
the positive control was used as a criterion to reject an air sample.

Air sampling sites. Air sampling sites were located in the Bradford Marsh, ON, Canada, which is characterized by organic (muck) soil (50 to $75 \%$ organic matter, $\mathrm{pH}$ 5.5-6.5), naturally infested with S. sclerotiorum and having a history of SRC. Data were collected in 2008, 2009, and 2011 at the experimental site 1 (E1), which represented the central area of the Bradford Marsh, and two commercial carrot fields, $\mathrm{C} 1$ and $\mathrm{C} 2$, representing the west and east regions of the marsh, respectively. In 2009 and 2011, an additional experimental site (E2) was included. 'Achieve', 'Cellobunch'. or 'Envy' carrot plants were direct-seeded in late May at the experimental sites at 80 seeds $\mathrm{m}^{-1}$ of row using a precision seeder on raised beds spaced $86 \mathrm{~cm}$ apart center to center, having a $40-\mathrm{cm}$ wide growing area containing three rows of carrot plants. Although differential cultivar susceptibility to $S$. sclerotiorum on carrot roots in storage has been reported (21), there is no documentation on foliage in field-grown carrot (32). The plots were maintained following Ontario standard management practices (44). Carrot plants were sprayed with mancozeb (2 kg of Dithane DG [1.5 kg a.i. ha ${ }^{-1}$; Dow Sciences, in a total volume of 400 liters ha-1) in early August in 2009 and 2011 to manage leaf blight caused by Alternaria dauci and Cercospora carotae. Pre-emergence (6 liters of Gesegard [prometryn at 2,880 g a.i. ha $^{-1}$ ]; Novartis Crop Protection Canada Inc., in a total volume of 400 liters $\left.\mathrm{ha}^{-1}\right)$ or post-emergence (500 $\mathrm{ml}$ of Lorox (linuron at $250 \mathrm{ml}$ a.i. $\mathrm{ha}^{-1}$ ); Dupont Canada Inc., in a total volume of 400 liters $\mathrm{ha}^{-1}$ ) broadleaf herbicides were used in combination with hand weeding for weed control. Commercial sites were direct-seeded by the growers in late May with the Cellobunch or 'Fontana' using a precision seeder at 45 to 48 seeds $\mathrm{m}^{-1}$ of row on raised beds $72 \mathrm{~cm}$ apart center to center. There were three rows of carrot plants in each bed. Sites were maintained by the growers following Ontario standard management practices (44). Air sampling at all sites began at $75 \%$ canopy closure.

Burkard Sampler. A Burkard Multi-Vial Cyclone Sampler (Burkard Manufacturing Co. Ltd.) was placed at E1 in a carrot plot measuring approximately 10 by $15 \mathrm{~m}$. Bioaerosol was collected into $1.5-\mathrm{ml}$ tubes at an air movement rate of 16.5 liters $\mathrm{min}^{-1}$ from 1000 to $1300 \mathrm{~h}$, because ascospore release has been reported to peak from 0900 to $1300 \mathrm{~h}(5,47)$. There were 13, 17, and 16 air sample dates collected in 2008, 2009, and 2011, respectively (Table 2). All air samples were stored dry at $-20^{\circ} \mathrm{C}$ prior to DNA extraction. To prepare air samples for DNA extraction, $100 \mathrm{mg}$ of $500-\mu \mathrm{m}$ glass beads and $100 \mu \mathrm{l}$ of CTAB were added to the collection tubes and vortexed for 10 min using a vortex adapter (MoBio Laboratories Inc.), followed by three freeze-thaw cycles as described above. Contents of the PowerBead tube were transferred to the collection tube and each air sample was spiked with $2 \times 10^{6}$ copies of the NTFT plasmid, followed by DNA extraction. Samples were kept frozen at $-20^{\circ} \mathrm{C}$.

Purified DNA from air samples was analyzed by qPCR to quantify $S$. sclerotiorum ascospores against the standard curve generated through the 10-fold serial dilution of known concentrations of ascospores. To confirm that $S$. sclerotiorum was specifically detected in air samples, the melt curve of each sample was verified for a single peak and 10 randomly chosen amplification reactions were sequenced. Amplified products were purified using Qiaquick spin columns (Qiagen Inc.). Amplified products were sequenced with the BigDye version 3.1 Ready Reaction Kit (Applied Biosystems) on an ABI 3730 DNA Analyzer (Applied Biosystems) at the University of Guelph Genomics Facility. Forward and reverse sequences were assembled, then aligned with the $S$. sclerotiorum mt SSU rRNA GenBank accession U07553 and sequences from positive controls generated by the Mit(i)_Ss F/R primer set on mycelia (isolate $\mathrm{C} 14$ ) and ascospores of S. sclerotiorum (isolate DL) using Geneious Pro software (v.5.4.3). Disease incidence was visually related to ascospore concentration to analyze the relationship between ascospore concentration and subsequent disease. Ascospore counts were expressed as ascospores per cubic meter of air (number of ascospores per collection tube $\times$
1,000 liters $\left.\mathrm{m}^{-3}\right) /\left(16.5\right.$ liters $\left.\mathrm{min}^{-1} \times 60 \mathrm{~min}^{-1} \times 3 \mathrm{~h}\right)$ to examine the relationship between ascospore counts and disease. Ascospore counts were expressed as the total number of ascospores per collection tube to compare air sampling methods.

BPT. The BPT consists of exposing 90-mm-diameter petri plates containing SSM to passively intercept bioaerosol $(5,50)$. The plates were placed $1 \mathrm{~m}$ above the soil surface on a covered stand located at approximately $45^{\circ}$, facing the prevailing winds for $3 \mathrm{~h}$ within the period 0930 to $1330 \mathrm{~h}$ at sites E1, E2, C1, and C2. At E1, the plates were in the same plot as the Burkard Sampler, within $10 \mathrm{~m}$ of the nearest plates. There were 20, 22, and 19 air sample dates collected in 2008, 2009, and 2011, respectively (Table 3). There were six replicate plates placed 2 to $5 \mathrm{~m}$ apart at each site. Exposed plates were evaluated $72 \mathrm{~h}$ after exposure, as described by Foster et al. (22). Other fungal species in bioaerosol able to germinate and produce acid resulting in the diagnostic yellow halos included Aspergillus, Botrytis, and Penicillium spp., potentially leading to falsepositive identifications. Single colonies identified as S. sclerotiorum were regularly subcultured onto individual plates containing SSM to confirm correct identification. The mean number of CFU for each site was used as an estimate of the number of airborne ascospores for each sampling date.

Andersen Sampler. An Andersen N-6 Single-Stage Sampler (Andersen Instruments Inc.) was positioned $1 \mathrm{~m}$ above the soil surface on a tripod. A vacuum pump operated by a $12-\mathrm{V}$ marine battery was used to actively deposit bioaerosol onto plates containing SSM placed inside the sampler. Three plates were each exposed for $10 \mathrm{~min}$ at one sampling location at E1, C1, and $\mathrm{C} 2$ that was in the same plot, and within $10 \mathrm{~m}$ of the BPT. The 3-by-10min sampling procedure was based on the manufacturer's recommendations. The Andersen Sampler was not evaluated at E2 due to time constraints of sampling at three sites within the peak ascospore deposition hours of 0900 to $1300 \mathrm{~h}$. There were 15, 16, and 13 air sample dates collected in 2008, 2009, and 2011, respectively (Table 3). Colonies arising from ascospores of S. sclerotiorum were identified as described above. The total number of ascospores collected on three plates per site, representing 30 min total sampling time, was used to estimate the number of airborne ascospores for each sampling date.

Disease assessments. Plants were evaluated for incidence of $\mathrm{SRC}$ as the percentage of plants in a 1-m-long section of the carrot bed (the assessment area) that had at least one diseased leaf or petiole, including tissues lodged on the furrow. There were six replicate assessment areas per site and each contained a blue plate. Mean disease incidence was used to analyze the relationship between ascospore count and SRC at each site. Disease was assessed weekly on an air sampling date from the initial BPT exposure until harvest.

Data analysis. To determine which method was most sensitive and consistent and best related to subsequent disease, ascospore counts were compared among the air sampling methods and sites to analyze consistency among sites in periods of no detection, date of first detection, dates that the BPT threshold was reached, and peaks in ascospore counts. Analyses of variance were performed on the cumulative number of ascospores detected at each site for the BPT and means were separated using Tukey's adjustment. There was a single replicate air sample count for each air sampling date using an Andersen or a Burkard Sampler; therefore, analysis of variance could not be conducted for these sampling methods and total numbers of ascospores are presented. Correlation analyses were used to determine the relationship between the number of ascospores detected using the qPCR assay and the mean number of ascospores detected using BPT. Statistical analyses were performed using the PROC CORR and PROC MIXED procedures of SAS (v. 9.2; SAS Institute) with a type I error of 0.05 .

\section{Results}

Primer design. A qPCR assay using SYBR Green I fluorescent dye was developed for $S$. sclerotiorum that detects and quantifies ascospores from air samples. As predicted, an amplicon of $122 \mathrm{bp}$ 
was generated by the $S$. sclerotiorum-specific primer set Mit(i)_Ss $\mathrm{F} / \mathrm{R}$ on mycelia and ascospores. Sequences of amplified products from mycelia and ascospores generated by the Mit(i)_Ss F/R primer set aligned $100 \%$ with the $S$. sclerotiorum intron of the $\mathrm{mt}$ SSU rRNA (U07553) and the mitochondrial sequence of strain 1980 (sequenced by the Broad Institute, Harvard University, Cambridge, MA).

Primer specificity. The Mit(i)_Ss F/R primer set detected 37 of 40 isolates of S. sclerotiorum, including detection of 29 of 30 isolates from the Bradford Marsh. The $\mathrm{Ct}$ values from the 37 detected isolates at $10 \mathrm{pg}$ of DNA were 20 to 33, of which 29 isolates were detected between $\mathrm{Ct}$ values of 20 and 24 (Table 1). The melt temperature of the amplified product from each positively identified isolate was consistent with the melt temperatures of the positive controls (e.g., 74.8 to $75.3^{\circ} \mathrm{C}$ ). Specificity tests with 19 of 21 fungi expected to be among the bioaerosol of the Bradford Marsh and other Ascomycota species produced no signals but the primer set did detect $S$. minor and $M$. vaccinii-corymbosi (Table 1). M. fructicola (G. Winter) Honey was detected at $\mathrm{Ct}$ values $>36$, above the $\mathrm{Ct}$ detection threshold of 34 for positive detection of S. sclerotiorum. The melt temperatures of the amplified product from $S$. minor and M. vaccinii-corymbosi differed by 0.9 to $1.5^{\circ} \mathrm{C}$ from the positive $S$. sclerotiorum controls. No amplification signals were detected in negative no-template controls.

Ascospore dilution series to establish a qPCR standard curve. A linear response was observed at a range of 0.5 to $5 \times 10^{4}$ ascospores of $S$. sclerotiorum, with Ct values of 17.2 to 33.7 along the 10-fold ascospore dilution series (Fig. 1). The highly reproducible $\mathrm{Ct}$ values had low standard deviations ( 0 to 0.3 of a $\mathrm{Ct}$ value), with approximately 3.5 cycle differences in $\mathrm{Ct}$ values between each 10-fold dilution. Although DNA from each technical replication of 0.5 ascospores of $S$. sclerotiorum was not detected, at least one technical replication was detected in each reaction. At DNA equivalent to 2.5 ascospores and greater, all technical replica- tions in each reaction were detected. The regression equation for the ascospore standard curve based on pooled data of the four replicate dilution series was $y=-3.378 \log (x)+33.17$, with an $R^{2}$ of $0.99, P<0.0001$, and efficiency of $98 \%$ (Fig. 1). The detection limit of the target amplicon was at a Ct value of $33.7 \pm 0.2(n=6)$; therefore, samples detected above a $\mathrm{Ct}$ value of 34 were assessed as negative. The NTFT plasmid affected the $\mathrm{Ct}$ value near the limit of the linear range of the dilution series, at 0.5 ascospores, but quantities of 5 ascospores and greater along the dilution curve were not affected by the presence of the NTFT plasmid.

Internal control. The NTFT F/R primer set for the internal control was specific for NTFT, and no amplification signals were detected in any of the reactions with the 22 fungi tested in this study. Among the 46 air samples, 6 were rejected either because the internal control was not detected or the $\mathrm{Ct}$ value varied $>2 \mathrm{Ct}$ values relative to the positive control of the plasmid extracted alone (Table 2). NTFT was not detected for 15 September 2009, and the $\mathrm{Ct}$ value for 8 October 2009 differed by more than $2 \mathrm{Ct}$ values of the positive control; however, these samples were accepted because, despite possible inhibition, ascospore detection was strong for both of these dates and $\mathrm{Ct}$ values were below the range associated with subsequent disease development. No amplification signals were detected in negative no-template controls.

qPCR of air samples. Ascospores of S. sclerotiorum were specifically detected in air samples analyzed by qPCR using the Mit(i)_Ss F/R primer set. Of the total 40 accepted air samples, the number of ascospores from 27 samples was detected within the linear range of the ascospore standard curve. Ascospores were not detected or were detected below the linear range of detection in 2 and 11 air samples, respectively (Table 2). The standard deviation of three technical replications was $<1$ for samples within the linear range of the ascospore standard curve, except for six dates, when the standard deviation was 1.12 to 1.51 . Outside of the linear range (Ct value greater than 34), standard deviations increased, ranging

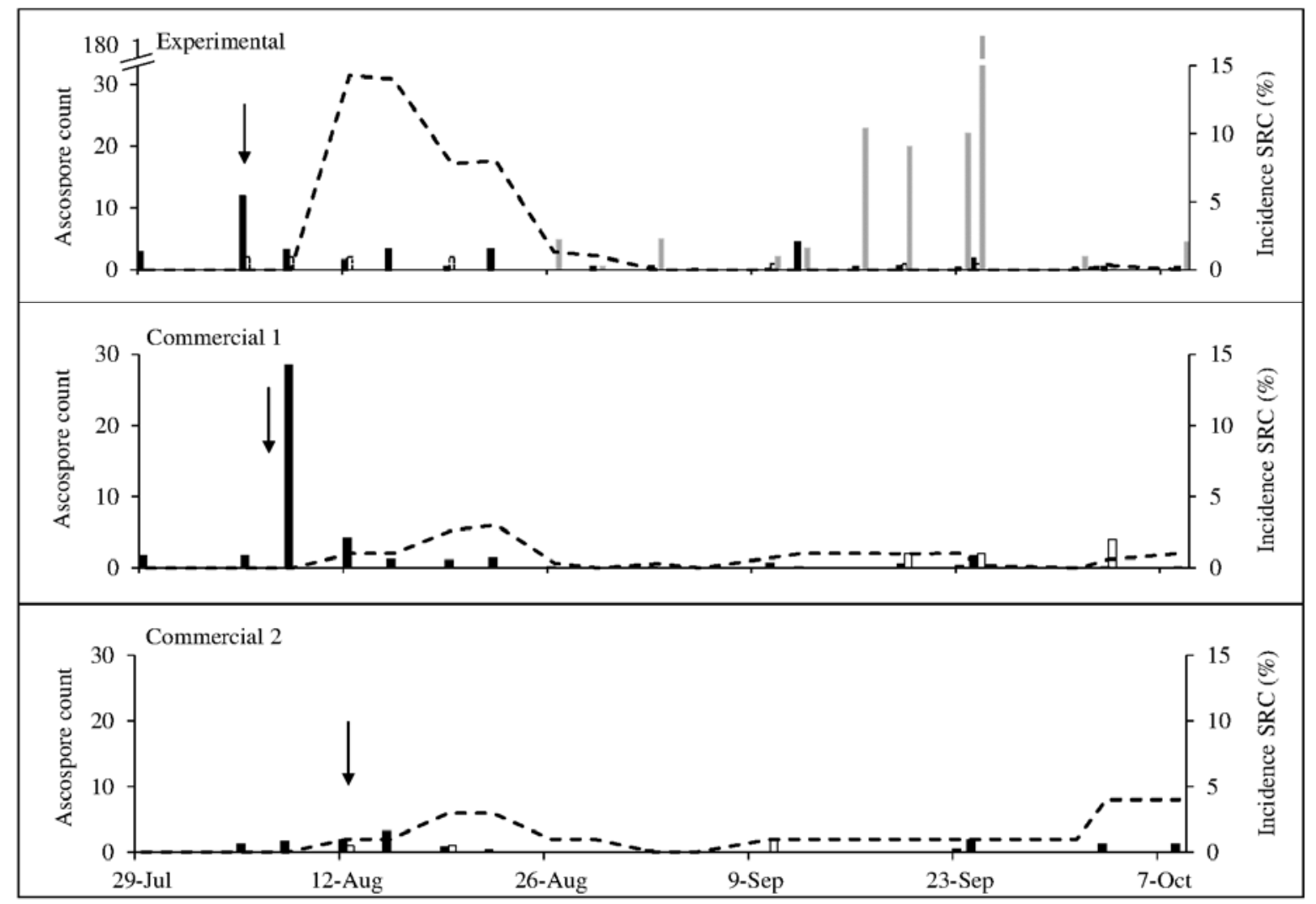

Fig. 3. Relationship between the incidence of Sclerotinia rot of carrot (SRC, dashed line) and the mean number of ascospores of Sclerotinia sclerotiorum detected using the blue plate test (BPT, solid column), a Burkard Multi-Vial Cyclone Sampler coupled with a qPCR assay (gray column), and an Andersen N-6 Single-Stage Sampler (open column) at three air sampling sites in the Bradford Marsh, Ontario in 2008. The Burkard Sampler was located at the experimental site alone and sampling began on 26 August. Arrows indicate canopy closure. 
from 0.1 to 2.7 (Table 2). The melt temperature of the single 122bp amplicon generated by Mit(i)_Ss F/R from air samples was within the range of the technical replications of the positive controls (Fig. 2). Sequences of amplified products from 10 randomly selected air samples aligned $100 \%$ with sequences generated by the Mit(i)_Ss F/R primer set on mycelia and ascospores of S. sclerotiorum, the mt SSU rRNA (U07553), and the complete mitochondrial sequence of strain 1980.

Based on visual analyses of the relationships among ascospore counts using the qPCR assay and disease incidence, initial disease was observed 8 and 34 days following detection of 9.5 and 2 ascospores $\mathrm{m}^{-3}$ of air in 2009 and 2011, respectively. In this current study, 2 and 9.5 ascospores $\mathrm{m}^{-3}$ of air corresponded to $\mathrm{Ct}$ values of 30.6 and 28.3, or 6 and 29 ascospores per collection tube, respectively. In 2008, the Burkard Sampler was installed late in the season, not permitting observation between ascospore counts and initial infection.

Air sampling methods to detect ascospores. Among the air sampling sites in 2008, the number of S. sclerotiorum ascospores detected using an Andersen Sampler, the BPT, and a Burkard Sampler coupled with the qPCR assay was 0 to 4,0 to 29 , and 0 to 178 , respectively (Table 3). From 12 to 24 September at E1, the qPCR assay indicated that ascospores were present in quantities at potential disease risk levels on four sampling dates, whereas the BPT almost reached the threshold on a single air sampling date. At E1, SRC was first observed on 12 August and varied from 8 to $14 \%$ until 22 August. Disease was reduced to $1 \%$ by late-August and was not observed in September until the end of the air sampling season on 8 October (Fig. 3). At $\mathrm{C} 1$ and $\mathrm{C} 2$, disease incidence varied from 0 to 3 and $4 \%$, respectively, throughout the growing season (Fig. 3).

In 2009, the number of ascospores detected daily using the BPT, Andersen Sampler, and Burkard Sampler/qPCR assay was 0 to 22, 0 to 13 , and 0 to 48, respectively (Table 3 ). From 30 July to 1 September at E1, each qPCR assay indicated that ascospores were present in quantities at potential disease risk levels and the BPT reached the SRC threshold on seven air sampling dates, followed by low levels of detection by both methods from 4 to 11 September. The qPCR assay detected another peak of ascospores on three air sampling dates from 15 September to 8 October, while the BPT did not detect a single ascospore during this period. At E1, SRC was first observed on 7 August, peaked at $12 \%$ on 17 August, and varied from 5 to $12 \%$ for the majority of the remainder of the season. At $\mathrm{C} 1$ and $\mathrm{C} 2$, disease incidence varied from 0 to 2 and 0 to $4 \%$, respectively, throughout the growing season (Fig. 4).

In 2011, lower numbers of ascospores were detected at the three sampling sites compared with 2008 and 2009. The number of ascospores detected using an Andersen Sampler, BPT, and Burkard Sampler/qPCR assay was 0 to 3,0 to 8 , and 0 to 6 , respectively (Table 3). At E1, the qPCR assay indicated that ascospores were present in quantities at potential disease risk levels on 20 July and 30 August, whereas the BPT threshold was not reached on any air sampling day. At E1, SRC was first observed on 23 August, increased to $14 \%$ by 9 September, and remained at this level for the remainder of the air sampling season. SRC was not observed at $\mathrm{C} 1$ and remained at $0 \%$ at $\mathrm{C} 2$ for most of the air sampling season, peaking at $0.5 \%$ on 9 and 13 September (Fig. 5). Correlation values between the number of ascospores detected using the qPCR assay and the BPT were insignificant for the three sampling years.

Over the three air sampling years at E1, the qPCR assay detected ascospores on each date that they were detected using the BPT, except for 15 August 2011. However, an average of less than one ascospore was detected using the BPT on this date, with five replicate blue plates not detecting any ascospores. The qPCR assay detected ascospores on 10 sampling dates when the $\mathrm{Ct}$ value was $<34$, the limit of the linear range of ascospore detection, when the BPT failed to detect any ascospores (Tables 2 and 3). Ct values were below 30.6, the range associated with subsequent disease development, for 6 of these 10 dates.

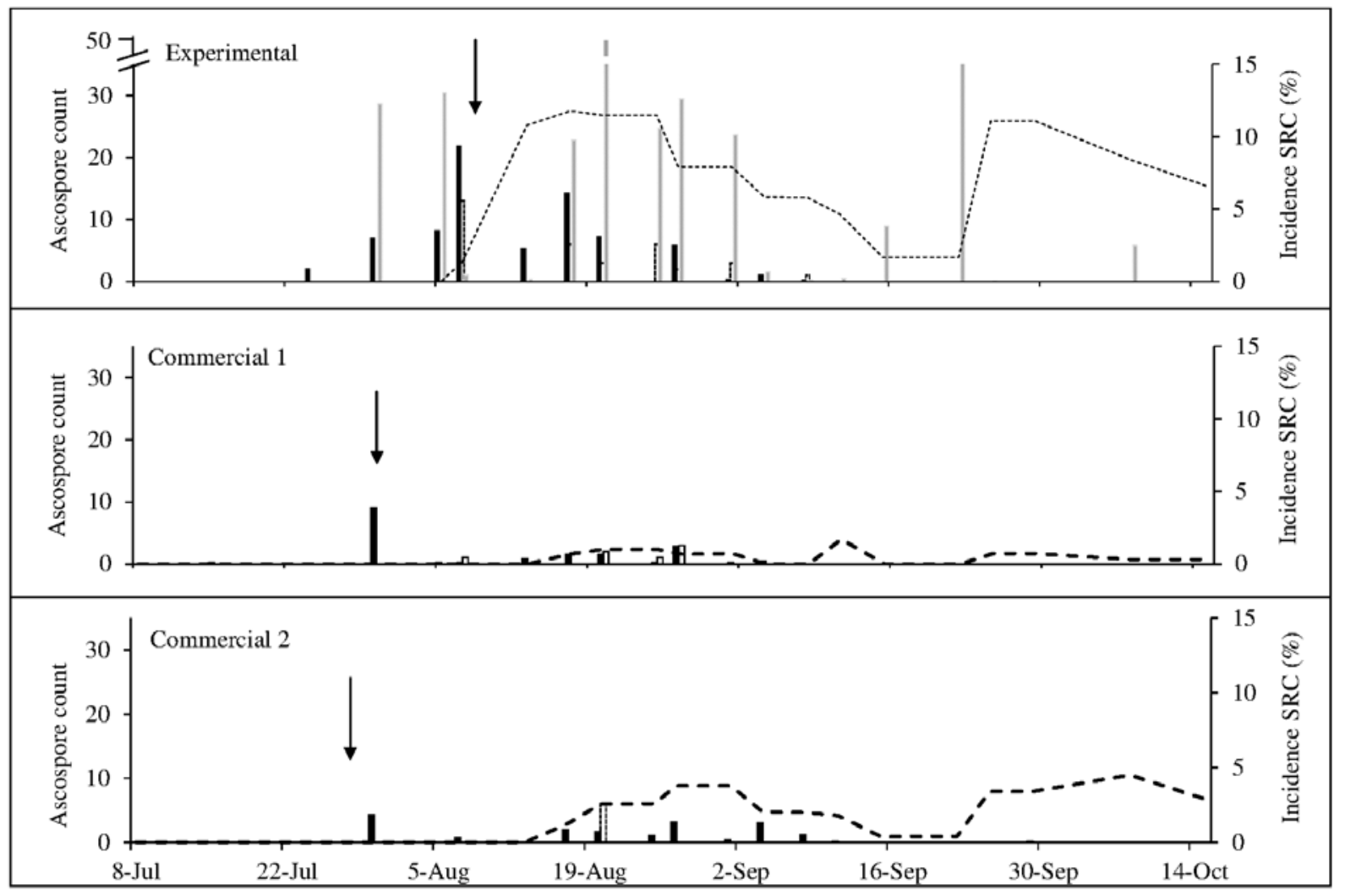

Fig. 4. Relationship between the incidence of Sclerotinia rot of carrot (SRC, dashed line) and the mean number of ascospores of Sclerotinia sclerotiorum detected using the blue plate test (BPT, solid column), a Burkard Multi-Vial Cyclone Sampler coupled with a qPCR assay (gray column), and an Andersen N-6 Single Stage Sampler (open column) at three air sampling sites in the Bradford Marsh, Ontario in 2009. The Burkard Sampler was located at the experimental site alone. Arrows indicate canopy closure. 


\section{Discussion}

This study was conducted to improve the SRC forecast model developed and validated in previous studies $(22,34)$ by evaluating methods based on the traditional use of exposing plates containing selective culture medium to the air and the use of DNA-based technologies to detect and quantify ascospores of $S$. sclerotiorum. This study developed a qPCR assay to rapidly and specifically identify airborne ascospores of $S$. sclerotiorum against a background of bioaerosol collected using a Burkard Sampler. The current ascospore detection method of the SRC forecast model relies on the $\mathrm{BPT}$, which is effective but requires 3 days to confirm the presence of $S$. sclerotiorum. The described $\mathrm{qPCR}$ assay coupled with a Burkard Sampler can potentially provide a diagnosis within $5 \mathrm{~h}$ of air sampling, further improving the efficacy of the current SRC forecast model. An Andersen Sampler consistently detected fewer ascospores than either the BPT or a Burkard Sampler coupled with the qPCR assay and was cumbersome to use. In general, bioaerosol sampling efficiency was low with the Andersen Sampler, because the number of colonies that developed on SSM was consistently low using the Andersen Sampler compared with the BPT. Often, colony growth was not observed on several sampling dates when abundant growth was observed using the BPT; thus, the Andersen Sampler was not considered further.

The qPCR assay showed that DNA from S. sclerotiorum ascospores could be efficiently extracted directly from air sample collection tubes using a commercial DNA extraction kit. Sensitivity was high, detecting DNA from the equivalent of less than one ascospore. The qPCR assay detected $93 \%$ of S. sclerotiorum isolates tested in this study. The Mit(i)_Ss F/R primer set was shown to be generally specific to $S$. sclerotiorum when tested against selected, closely related species of Ascomycota and a range of other fungi expected to be among the bioaerosol. Although the assay detected $M$. vaccinii-corymbosi and $S$. minor, the latter species is not known to produce spores and only reproduces by myceliogenic germination of sclerotia $(28,46)$ and, therefore, is not expected to be airborne. $M$. vaccinii-corymbosi is a pathogen of blueberry (48), a crop which has specific and narrow optimal production requirements (45); therefore, blueberry is generally not expected to be found near commercial crops in most regions that are susceptible to $S$. sclerotiorum. Furthermore, sequencing of air samples confirmed that $S$. sclerotiorum was specifically detected. Differences in melt curve temperatures between $S$. minor or $M$. vaccinii-corymbosi and $S$. sclerotiorum could also indicate falsepositive identifications.

The Mit(i)_Ss F/R primer set detected $93 \%$ of isolates of S. sclerotiorum from diverse hosts and geographic areas but detected almost all of the isolates from a single region, the Bradford March. This primer pair failed to detect 1 of 40 isolates originating from bean, carrot, and lettuce collected in the Bradford Marsh. The target sequence of the primer set is a mitochondrial group one intron of the mt SSU rDNA. The presence of nuclear and mitochondrial group one introns is not conserved among isolates in a species, and their absence from isolates within a population has been reported for M. fructicola (19) and S. sclerotiorum (31), respectively. It is possible that $S$. sclerotiorum ascospores lacking the intron were present in air samples; however, the relationship between ascospore detection and subsequent SRC suggest that the low prevalence of isolates lacking the intron shouldn't significantly affect ascospore numbers detected in air samples. In the 2 years when the Burkard Sampler was operational prior to the initial observation of SRC, disease was observed 8 days following detection of 9.5 ascospores $\mathrm{m}^{-3}$ of air, whereas disease was observed after 34 days following detection of 2 ascospores $\mathrm{m}^{-3}$ of air.

Strong relationships between inoculum levels and subsequent disease are mandatory for confident disease prediction using fore-

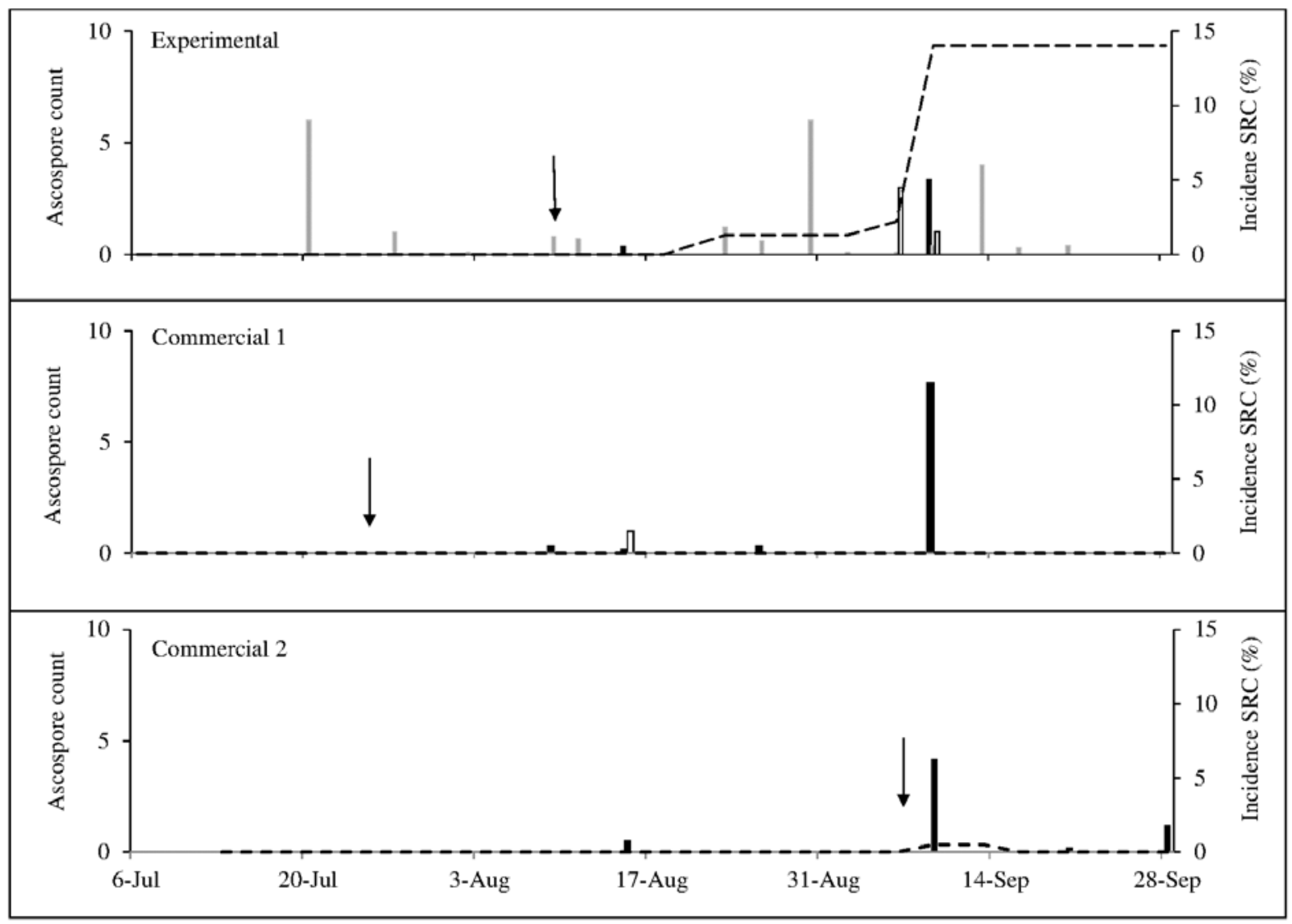

Fig. 5. Relationship between the incidence of Sclerotinia rot of carrot (SRC, dashed line) and the mean number of ascospores of Sclerotinia sclerotiorum detected using the blue plate test (BPT, solid column), a Burkard Multi-Vial Cyclone Sampler coupled with a qPCR assay (gray column), and an Andersen N-6 Single Stage Sampler (open column) at three air sampling sites in the Bradford Marsh, Ontario in 2011. The Burkard Sampler was located at the experimental site alone. Arrows indicate canopy closure. 
casting models based on detection and quantification of inoculum. The high number of ascospores detected at E1 in 2009 by the BPT and qPCR assay reflected the subsequent high incidence of SRC, which surpassed $10 \%$; thus, both methods would have accurately predicted SRC in the year when disease was most severe. Correctly predicting high disease risk is of foremost importance because underestimating disease can have a greater impact on growers than overestimation. Potential yield losses as a result of a missed fungicide application or other management practice can be greater than economic losses from an unnecessary fungicide application, which can still be cost effective (30). In general, detection of low ascospore counts by the BPT assay were followed by low incidences of SRC at all sampling sites. However, in 2011 at E1, the BPT and qPCR assay underestimated disease because the BPT threshold was never reached and the qPCR assay indicated risk of SRC developing on a single air sampling date, whereas incidence of SRC reached $14 \%$. This is consistent with prediction models based on detecting $S$. sclerotiorum, whereby higher rates of prediction accuracy were observed when low disease risk was predicted $(14,52)$. In these two studies, incorrect predictions tended to underestimate disease risk rather than overestimate it.

Deciding among the BPT, Burkard Sampler, or risk algorithm to incorporate into the SRC forecast model depends on the resources available. Implementing the risk algorithm requires soil moisture sensors connected to a datalogger to automate summing the risk points, and provides an immediate prediction based on the sum of the risk points from the previous 7 days (22). Additionally, minimal human resources and skills are required for monitoring the risk algorithm. Forecast models based on risk algorithms have been shown to accurately predict low and high disease risk $(18,30)$, although one study demonstrated that predicting Sclerotinia stem rot of canola was more accurate using petal infestation compared with two versions of a risk algorithm (37). Forecast models based on measuring environmental and cropping variables can predict the period of carpogenic germination $(10,17,28,58)$; they do not quantity airborne ascospores, which has been shown to influence subsequent disease $(6,22,27,40,49)$. The BPT quantifies airborne ascospores but is laborious and more costly to implement than the risk algorithm, because it requires the preparation of media and a scout to place, retrieve, and evaluate the plates. Foster et al. (22) concluded that substituting the BPT with the risk algorithm was more practical to predict SRC due to the labor-intense nature of the BPT and the 3-day delay in detection, which could result in missing the optimum time for fungicide application or other management practices.

A Burkard Sampler coupled with a qPCR assay is the most resource-intensive of the detection methods. Major capital costs include a Burkard Sampler and a qPCR system. Operational costs include DNA extraction and qPCR, which can be completed by a commercial facility. The advantage of a Burkard Sampler coupled with qPCR is quick sample turnover. Additionally, a Burkard Sampler operates continuously for up to 1 week; therefore, samples need only be retrieved on the day of analysis and samples from more than one air sampling date can be analyzed simultaneously, providing additional data with minimal extra costs. A Burkard Sampler operates at a known air flow rate, permitting ascospore concentrations to be standardized and resulting in consistent determination of the quantity of ascospores between air sampling dates. The BPT and qPCR assay can be applied to numerous hosts of Sclerotinia diseases, while the risk algorithm is limited to SRC.

In this current study, initial SRC was observed after ascospore counts reached 2 and 9.5 ascospores $\mathrm{m}^{-3}$ of air using a Burkard Sampler coupled with the qPCR assay. This is consistent with a study conducted in England by Rogers et al. (49). Over two growing seasons, when ascospore concentrations remained below 1 ascospore $\mathrm{m}^{-3}$ of air over two cropping seasons, levels of Sclerotinia stem rot of canola remained low $(0.1 \%)$. In 2007, the third air sampling season, a Sclerotinia stem rot of canola epidemic $(5.5 \%)$ occurred (24), which was associated with concentrations of airborne ascospores of $S$. sclerotiorum fluctuating from 2 to 12 asco- spores $\mathrm{m}^{-3}$ of air; concentrations on 15 of 29 air sampling dates were greater than 4 ascospores $\mathrm{m}^{-3}$ of air (49).

Forecasting models for diseases caused by $S$. sclerotiorum based on inoculum detection should also consider cropping and environmental variables when predicting subsequent risk of disease. The cropping and environmental conditions that are conducive to disease development can change from the time of carpogenic germination to ascospore germination, particularly if extrinsic sources of ascospores are detected in fields that originated from apothecia produced under different cropping and environmental conditions. Extrinsic sources of ascospores have been suggested as a contributing source of inoculum in bean $(10)$, canola $(25,43)$, lettuce $(46)$, and potato, where the extrinsic source was uncropped land (27). Even though in-field sources of ascospores were suggested as the principal source of inoculum in SRC $(22,34)$, extrinsic sources cannot be excluded as contributing to disease because, in this study, ascospores were often detected at a site prior to canopy closure. Although relationships between the BPT or Burkard Sampler coupled with a qPCR assay and disease incidence indicated that these sampling methods detected ascospores with equal accuracy, ascospore counts did not correspond to subsequent disease observed at some sites in some years, indicating that it is important not to use inoculum detection as the sole indicator in predicting subsequent disease risk.

The qPCR assay developed in this study has the potential to be a rapid and reliable method to detect airborne ascospores of $S$. sclerotiorum and indicate the subsequent risk of SRC developing. Although there are numerous studies describing qPCR to detect and quantify microorganisms from environmental samples $(7,9,26$, 36,42 ), only a few studies relate the quantity of inoculum detected using qPCR with subsequent disease to determine a disease risk threshold $(8,16)$. The results from this assay indicate that ascospore counts determined using the qPCR assay are related to subsequent disease. Of the three air sampling methods evaluated in this study, the BPT and Burkard Sampler coupled with the qPCR assay were comparable indicators of subsequent severity of SRC. Although initial observations between the concentration of ascospores and SRC suggest that the qPCR assay is an effective method to predict risk of SRC, an upscaled evaluation of a Burkard Sampler coupled with a qPCR assay is required to conclude the accuracy of this method to quantify airborne ascospores. It is difficult to suggest a definitive ascospore count-disease relationship based on 3 years of air sampling at a single site. Further validation of the relationship between ascospore counts and disease and determination of a threshold are necessary before confident integration of this qPCR assay into the SRC forecast model.

\section{Acknowledgments}

This research was funded by the Natural Sciences and Engineering Research Council of Canada, and the OMAFRA and University of Guelph partnership under the Plant Production Systems Program. We thank the farmers who allowed us access to their fields, staff at the Muck Crops Research Station for assisting with air sampling logistics, and J. Zhang of the Genomics Facility, University of Guelph for excellent technical assistance.

\section{Literature Cited}

1. Abawi, G. S., and Grogan, R. G. 1975. Source of primary inoculum and effects of temperature and moisture on infection of beans by Whetzelinia sclerotiorum. Phytopathology 65:300-309.

2. Abawi, G. S., and Grogan, R. G. 1979. Epidemiology of diseases caused by Sclerotinia species. Phytopathology 69:899-904.

3. Andersen, A. A. 1958. New sampler for the collection, sizing, and enumeration of viable airborne particles. J. Bacteriol. 76:471-484.

4. Bassett, I. J., Crompton, C. W., and Parmelee, J. A. 1978. An Atlas of Airborne Pollen Grains and Common Fungus Spores of Canada. Printing and Publishing Supply and Services Canada., Hull, QC, Canada.

5. Ben-Yephet, Y., and Bitton, S. 1985. Use of a selective medium to study the dispersal of ascospores of Sclerotinia sclerotiorum. Phytoparasitica 13:3340.

6. Ben-Yephet, Y., and Siti, E. 1987. Lettuce drop caused by inoculum of Sclerotinia sclerotiorum blown-in from a distance. Phytoparasitica 15:69-71.

7. Bilodeau, G. J., Koike, S. T., Uribe, P., and Martin, F. N. 2012. Development of an assay for rapid detection and quantification of Verticillium dahliae in soil. Phytopathology 102:331-343. 
8. Bithell, S. L., McKay, A., Butler, R. C., Ophel-Keller, H., Ophel-Keller, K., Hartley, D., and Cromey, M. 2012. Predicting take-all severity in secondyear wheat using soil DNA concentrations of Gaeumannomyces graminis var. tritici determined with qPCR. Plant Dis. 96:443-451.

9. Blanco-Meneses, M., and Ristaino, J. B. 2011. Detection and quantification of Peronospora tabacina using a real-time polymerase chain reaction assay. Plant Dis. 95:673-682.

10. Boland, G. J., and Hall, R. 1987. Epidemiology of white mold of white bean in Ontario. Can. J. Plant Pathol. 9:218-224.

11. Boland, G. J., and Hall, R. 1988. Epidemiology of Sclerotinia stem rot of soybean in Ontario. Phytopathology 78:1241-1245.

12. Boland, G. J., and Hall, R. 1988. Relationships between the spatial pattern and number of apothecia of Sclerotinia sclerotiorum and stem rot of soybean. Plant Pathol. 37:329-336.

13. Bolton, M. D., Thomma, B. P. H. J., and Nelson, B. D. 2006. Sclerotinia sclerotiorum (Lib.) de Bary: biology and molecular traits of a cosmopolitan pathogen. Mol. Plant Pathol. 7:1-16.

14. Bom, M., and Boland, G. J. 2000. Evaluation of disease forecasting variables for Sclerotinia stem rot (Sclerotinia sclerotiorum) of canola. Can. J. Plant Sci. 80:889-898.

15. Carbone, I., Anderson, J. B., and Kohn, L. M. 1995. A group-I intron in the mitochondrial small subunit ribosomal RNA gene of Sclerotinia sclerotiorum. Curr. Genet. 27:166-176.

16. Carisse, O., Tremblay, D. M., Lévesque, C. A., Gindro, K., Ward, P., and Houde, A. 2009. Development of a TaqMan real-time PCR assay for quantification of airborne conidia of Botrytis squamosa and management of Botrytis leaf blight of onion. Phytopathology 99:1273-1280.

17. Clarkson, J. P., Phelps, K., Whipps, J. M., Young, C. S., Smith, J. A., and Watling, M. 2004. Forecasting Sclerotinia disease on lettuce: toward developing a prediction model for carpogenic germination of sclerotia. Phytopathology 94:268-279.

18. Clarkson, J. P., Phelps, K., Whipps, J. M., Young, C. S., Smith, J. A., and Watling, M. 2007. Forecasting Sclerotinia disease on lettuce: a predictive model for carpogenic germination of Sclerotinia sclerotiorum sclerotia. Phytopathology 97:621-631.

19. Côté, M. J., Meldrum, A. J., and Tardiff, M. C. 2004. Variations in sequence and occurrence of SSU rDNA group I introns in Monilinia fructicola isolates. Mycologia 96:240-248.

20. Edmonds, R. L. 1972. Collection efficiency of rotorod samplers for sampling fungus spores in the atmosphere. Plant Dis. Rep. 56:704-708.

21. Finlayson, J. E., Pritchard, M. K., and Rimmer, S. R. 1989. Electrolyte leakage and storage decay of five carrot cultivars in response to infection by Sclerotinia sclerotiorum. Can. J. Plant Pathol. 11:313-316.

22. Foster, A. J., Kora, C., McDonald, M. R., and Boland, G. J. 2011. Development and validation of a disease forecast model for Sclerotinia rot of carrot. Can. J. Plant Pathol. 33:187-201.

23. Gadoury, D. M., and MacHardy, W. E. 1983. A 7-day recording volumetric spore trap. Phytopathology 73:1526-1531.

24. Gladders, P., Ginsburg, D., and Smith, J. A. 2008. Sclerotinia in Oilseed Rape-A Review of the 2007 Epidemic in England. Home Grown Cereals Authority, Cambridge, UK.

25. Gugel, R. K., and Morrall, R. A. A. 1986. Inoculum-disease relationships in Sclerotinia stem rot of rapeseed in Saskatchewan. Can. J. Plant Pathol. 8:89-96.

26. Ha, Y. S., Kim, J. S., Denny, T. P., and Schell, M. A. 2012. A rapid, sensitive assay for Ralstonia solanacearum race 3 biovar 2 in plant and soil samples using magnetic beads and real-time PCR. Plant Dis. 96:258-264.

27. Hammond, C. N., Cummings, T. F., and Johnson, D. A. 2008. Deposition of ascospores of Sclerotinia sclerotiorum in and near potato fields and the potential to impact efficacy of a biocontrol agent in the Columbia Basin. Am. J. Potato Res. 85:353-360.

28. Hao, J. J., Subbarao, K. V., and Duniway, J. M. 2003. Germination of Sclerotinia minor and S. sclerotiorum sclerotia under various soil moisture and temperature combinations. Phytopathology 93:443-450.

29. Harikrishnan, R., and del Río, L. E. 2008. A logistic regression model for predicting risk of white mold incidence on dry bean in North Dakota. Plant Dis. 92:42-46.

30. Koch, S., Dunker, S., Kleinhenz, B., Röhrig, M., and von Tiedemann, A. 2007. A crop loss-related forecasting model for Sclerotinia stem rot in winter oilseed rape. Phytopathology 97:1186-1194.

31. Kohn, L. M., Stasovski, E., Carbone, I., Royer, J., and Anderson, J. B. 1991. Mycelial incompatibility and molecular markers identify genetic variability in field populations of Sclerotinia sclerotiorum. Phytopathology 81:480485 .

32. Kora, C., McDonald, M. R., and Boland, G. J. 2003. Sclerotinia rot of carrot: an example of phenological adaptation and bicyclic development by Sclerotinia sclerotiorum. Plant Dis. 87:456-470
33. Kora, C., McDonald, M. R., and Boland, G. J. 2005. Epidemiology of Sclerotinia rot of carrot caused by Sclerotinia sclerotiorum. Can. J. Plant Pathol. 27:245-258.

34. Lievens, B., Brouwer, M., Vanachter, A. C. R. C., Cammue, B. P. A., and Thomma, B. P. H. J. 2006. Real-time PCR for detection and quantification of fungal and oomycete tomato pathogens in plant and soil samples. Plant Sci. 171:155-165.

35. Lievens, B., and Thomma, B. P. H. J. 2005. Recent developments in pathogen detection arrays: implications for fungal plant pathogens and use in practice. Phytopathology 95:1374-1380.

36. Makowski, D., Taverne, M., Bolomier, J., and Ducarne, M. 2005. Comparison of risk indicators for Sclerotinia control in oilseed rape. Crop Prot. 24:527-531

37. Mbofung, G. C. Y., Fessehaie, A., Bhattacharyya, M. K., and Leandro, L. F. S. 2011. A new TaqMan real-time polymerase chain reaction assay for quantification of Fusarium virguliforme in soil. Plant Dis. 95:1420-1426.

38. McCartney, H. A., and Lacey, M. E. 1992. Release and dispersal of Sclerotinia ascospores in relation to infection. Proc. Brighton Crop 1:109-116.

39. McCartney, H. A., and Lacey, M. E. 1999. Timing and infection of sunflowers by Sclerotinia sclerotiorum and disease development. Aspects Appl. Biol. 56:151-156.

40. Mila, A. L., and Yang, X. B. 2008. Effects of fluctuating soil temperature and water potential on sclerotia germination and apothecial production of Sclerotinia sclerotiorum. Plant Dis. 92:78-82.

41. Montes-Borrego, M., Muñoz-Ledesma, F. J., Jiménez-Díaz, R. M., and Landa, B. B. 2011. Real-time PCR quantification of Peronospora arborescens, the opium poppy downy mildew pathogen, in seed stocks and symptomless infected plants. Plant Dis. 95:143-152.

42. Morrall, R. A. A., and Dueck, J. 1982. Epidemiology of Sclerotinia stem rot of rapeseed in Saskatchewan. Can. J. Plant Pathol. 4:161-168.

43. OMAFRA. 2011. Berry Crops. Fruit Production Recommendations 201011. Publication 360. Ontario Ministry of Agriculture, Food and Rural Affairs, Guelph, ON, Canada.

44. OMAFRA. 2011. Carrots. Vegetable Production Recommendations 2010 2011. Publication 363. Ontario Ministry of Agriculture, Food and Rural Affairs, Guelph, ON, Canada.

45. Patterson, C. L., and Grogan, R. G. 1985. Differences in epidemiology and control of lettuce drop caused by Sclerotinia minor and S. sclerotiorum. Plant Dis. 69:766-770.

46. Qandah, I. S., and Del Río Mendoza, L. E. 2011. Temporal dispersal patterns of Sclerotinia sclerotiorum ascospores during canola flowering. Can J. Plant Pathol. 33:159-167.

47. Ramsdell, D. C., Nelson, J. W., and Myers, R. L. 1975. Mummy berry disease of highbush blueberry: epidemiology and control. Phytopathology 65:229-232.

48. Rogers, S. L., Atkins, S. D., and West, J. S. 2009. Detection and quantification of airborne inoculum of Sclerotinia sclerotiorum using quantitative PCR. Plant Pathol. 58:324-331.

49. Steadman, J. R., Marcinkowska, J., and Rutledges, S. 1994. A semi-selective medium for isolation of Sclerotinia sclerotiorum. Can. J. Plant Pathol. 16:68-70

50. Turkington, T. K., and Morrall, R. A. A. 1993. Use of petal infestation to forecast Sclerotinia stem rot of canola: the influence of inoculum variation over the flowering period and canopy density. Phytopathology 83:682-689.

51. Turkington, T. K., Morrall, R. A. A., and Gugel, R. K. 1991. Use of petal infestation to forecast Sclerotinia stem rot of canola: evaluation of early bloom sampling, 1985-90. Can. J. Plant Pathol. 13:50-59.

52. Twengström, E., Sigvald, R., Svensson, C., and Yuen, J. 1998. Forecasting Sclerotinia stem rot in spring sown oilseed rape. Crop Prot. 17:405-411.

53. Vaerman, J. L., Saussoy, P., and Ingargiola, I. 2004. Evaluation of real-time PCR data. J. Biol. Regul. Homeost. Agents 18:212-214.

54. Ward, E., Kanyuka, K., Motteram, J., Kornyukhin, D., and Adams, M. J. 2005. The use of conventional and quantitative real-time PCR assays for Polymyxa graminis to examine host plant resistance, inoculum levels and intraspecific variation. New Phytol. 165:875-885.

55. Wegulo, S. N., Sun, P., Martinson, C. A., and Yang, X. B. 2000. Spread of Sclerotinia stem rot of soybean from area and point sources of apothecial inoculum. Can. J. Plant Sci. 80:389-402.

56. Williams, R. H., Ward, E., and McCartney, H. A. 2001. Methods for integrated air sampling and DNA analysis for detection of airborne fungal spores. Appl. Environ. Microbiol. 67:2453-2459.

57. Wu, B. M., and Subbarao, K. V. 2008. Effects of soil temperature, moisture, and burial depths on carpogenic germination of Sclerotinia sclerotiorum and S. minor. Phytopathology 98:1144-1152.

58. Yin, Y., Ding, L., Liu, X., Yang, J., and Ma, Z. 2009. Detection of Sclerotinia sclerotiorum in planta by a real-time PCR assay. J. Phytopathol. 157:465-469. 